\title{
DYNAMIC MODEL OF INSURANCE COMPANY'S MANAGEMENT
}

\author{
ANDRE FRISQUE
}

Belgium

In this paper, we are interested in a model related to a number of periods of Company's activity.

Optimal Policy of Dividends-Objective of the Insurance COMPANY.

The Company calculates an amount $s$ which then could be given as a supplementary interest to the shareholders. This calculated amount is taken from the risk reserve. Let us assume the risk reserve $=S$ at the beginning of an operating period. If the Company gives an amount $s$ to the shareholders, then the risk reserve is $S-s$. (Borch r972; Seal r969).

We must determine the best policy of dividends, that is a rule which determines the payments to be made each year to the shareholders of the Company, maximising a definite criterion.

The problem of dividends must be approached in the "dynamic programming manner". Indeed, the payments of dividends have an effect upon further gains of the Company and its capacity to pay dividends in the future.

The objective of the Company is, for example, maximising the average utility of the dividend payments, which is calculated according to the distribution of claims. (Borch I964a; Wolff I966).

\section{Description OF the Model.}

\section{The shareholders' order of preferences}

We first have to represent the preferences of the shareholders by a collective utility function representing the individual preferences in a rational manner. We will assume that all shareholders have the same preferences regarding the system of dividend payments. 
Let $U\left(s_{1}, s_{2}, \ldots s_{j}, \ldots \ldots\right)$ represent the shareholders' order of preferences in various systems of dividend payments $\left(s_{1}, s_{2}, \ldots\right.$, $\left.s_{j}, \ldots\right)$ where $s_{j}$ denotes the payments of dividend made by the Company during the year $j$.

We assume that $U$ is of the following form:

$U\left(s_{1}, s_{2}, \ldots, s_{j}, \ldots\right)=u\left(s_{1}\right)+v \cdot U\left(s_{2}, s_{3}, \ldots, s_{j}, \ldots\right)$ (Hakansson 1966)

where $u\left(s_{1}\right)$ denotes the shareholders' oneperiod utility function; $v$ is a factor expressing the shareholders' preferences for an early dividend $(0<v<\mathrm{I})$;

$U\left(s_{2}, s_{3}, \ldots, s_{j}, \ldots\right)$ denotes the prospective utility of the dividend program.

We now have, recurring

$$
U\left(s_{1}, s_{2}, \ldots, s_{j}, \ldots\right)=\sum_{k-1}^{\infty} \eta^{k-1} E[u(s k)]
$$

where

$F(x)=P(X \leqslant x)$ is the distribution function of the variable $X$ amount of claims to be paid;

$E \quad$ is the expected value of $X$.

We assume that $F(x)$ is the same in all operating periods, that is $X$ is distributed identically in all periods.

The objective of the Company

The objective of the Company may be formulated

$$
\operatorname{Max} U\left(s_{1}, s_{2}, \ldots, s_{j}, \ldots\right)=\operatorname{Max} \sum_{j-1}^{\infty} v^{j-1} E[u(s j)]
$$

As basis of our calculations, we assumed the first operating period of the Company. We may also consider any period $j$ and then we write:

$$
\operatorname{Max} U\left(s_{j}, s_{j+1}, s_{j+2}, \ldots\right)=\operatorname{Max} \sum_{j}^{\infty} \eta^{j-1} E[u(s j)]
$$


The relation between two successive risk reserves

The relation between the risk reserve of the Company at two succeeding points of decision is given by

$$
s_{j+1}=s_{j}-s_{j}+k_{1 j}\left(P-\int_{0}^{\infty} x d F(x)\right)
$$

We use the following notation:

$S_{j}=$ the risk reserve of the Company at the point of decision $j$;

$s_{j}=$ the amounts of dividends paid at the point of decision $j$;

$I^{\prime} \quad=$ the amount of received premiums during the period $j$;

$k_{1, j}=$ the part of the portfolio, retained by the Company in a quota reinsurance system.

\section{Decision variables and constraints}

The Company has two decision variables in each operating period: $s_{j}$ and $k_{1, j}$. The decisions are taken at the beginning of each period.

We consider the following constraints:

$$
0 \leqslant s_{j} \leqslant S_{j} ; \quad 0 \leqslant k_{1, j} \leqslant I .
$$

\section{The functional equation}

We introduce the function $U_{j}\left(S_{j}\right)$ denoting the discounted average utility of the dividends $s_{j}, s_{j+1}, \ldots$ evaluated at decision points $j, j+\mathrm{r}, \ldots$ when initial risk reserve is $S_{j}$ and an optimal policy is followed with respect to payment of dividends in all subsequent periods.

The principle of optimality in dynamic programming holds that whatever the initial state and the initial decision, future decisions must constitute an optimal policy with respect to the state resulting from the first decision. (Bellman I96I).

Applying the principle of optimality in dynamic programming, the dividends' decision problem at decision point $j$ can be formulated by the following equation:

$$
U_{j}\left(S_{j}\right)=\operatorname{Max}_{\substack{o \leqslant s_{j} \leqslant S_{j} \\ o \leqslant k_{1, j} \leqslant 1}}\left[u\left(s_{j}\right)+v \int_{0}^{\infty} U_{j+1}\left(S_{j}-s_{j}+k_{1, j}(P-x)\right) d F(x)\right]
$$


As a matter of fact, if the Company pays dividend $s_{j}$ at the beginning of the period $j$, it then has, at the beginning of the $\operatorname{period} j+\mathbf{I}$,

$$
S_{j}+k_{1, j}\left(P-\int_{\varepsilon}^{\infty} x d F(x)-s_{j}\right.
$$

The decisions relating to $s_{j+1}, s_{j+2}, s_{j+3}, \ldots$ and $k_{1, j+1}, k_{1, j+2}$, $k_{1, j+3}, \ldots$ must constitute an optimal policy. Furthermore, the optimal payment $s j$ and the value of $k_{1, j}$ must certainly maximise the utility of $s_{j}$ and the discounted average utility of the subsequent payments.

We must have the inequality

$$
\int_{0}^{\infty}\left[S_{j}-s_{j}+k_{1, j}(P-x)\right] d F(x) \geqslant 0
$$

We also suppose

$$
s_{j}=s_{j}\left(S_{j}\right)
$$

The problem is therefore to find a dividend function $s_{j}\left(S_{j}\right)$ and a function $k_{1, j}$ maximising the expression in brackets in (I), verifying the relation (2).

Practical resolution of the functional Equation.

Hypothesis concerning $u(s)$

We assume that the shareholders' preferences as to a single operating period may be represented by the utility function. $u(s)=s^{\gamma}(0<\gamma<I)$. This function is a concave function of $s$ $(s>0)$, which implies that the shareholders have a risk aversion.

The functional equation is then

$$
U_{j}\left(S_{j}\right)=\operatorname{Max}_{\substack{o \leqslant s_{j} \leqslant S_{j} \\ o \leqslant k_{1, j} \leqslant 1}}\left[s_{j}^{\gamma}+v \int_{0}^{\infty} U_{j+1}\left(S_{j}-s_{j}+k_{1, j}(P-x)\right) d F(x)\right]
$$

We take $\gamma=\frac{1}{2}$.

Special "probability distribution of claims"

We assume that the claim variable takes the values $o$ and 2 , respectively with the probabilities $p$ and $q(p>q)$. We take $P^{P}=\mathrm{I}$. (Borch, x964b). 


\section{Method of resolution}

The method of resolution is the method of successive approximations. We consider successively a horizon limited to I year, 2 years, 3 years, $\ldots, N$ years and also an unlimited horizon, if we take $N$ infinite.

The functional equation is then:

$$
\begin{aligned}
& U_{N}(S)=\operatorname{Max}_{0 \leqslant s_{N} \leqslant S}\left\{s_{N}^{1 / 2}+v\left[p U_{N-1}\left(S-s_{N}+k_{1, N}\right)+q U_{N-1}\right.\right. \\
& \left.\left.\begin{array}{l}
o \leqslant s_{N} \leqslant S \\
o \leqslant k_{1, N} \leqslant 1
\end{array} \quad\left(S-s_{N}-k_{1, N}\right)\right]\right\}
\end{aligned}
$$

$N$ denotes the number of years corresponding to the horizon.

We have the relation:

$$
\left(S-s_{N}+k_{1, N}\right) p+\left(S-s_{N}-k_{1, N}\right) q \geqslant 0
$$

Indeed, the first member of this inequality is at least equal to $k_{1, N}(p-q) \geqslant 0$.

Let us replace $N$ by $1,2,3, \ldots, N$ finite or infinite.

$$
U_{1}(S)=\operatorname{Max}_{\substack{0 \leqslant s_{1} \leqslant S \\ 0 \leqslant k_{1,1} \leqslant 1}} s_{1}^{1 / 2}=S^{1 / 2} .
$$

In effect, $U_{0}$ (any amount) $=0 ; k_{1,1}$ any figure.

$$
U_{2}(S)=\operatorname{Max}_{\substack{o \leqslant s_{2} \leqslant S \\ o \leqslant k_{1,2} \leqslant 1}}\left\{s_{2}^{1 / 2}+v\left[p U_{1}\left(S-s_{2}+k_{1,2}\right)+q U_{1}\left(S-s_{2}-k_{1,2}\right)\right]\right\}
$$

Seeing that $U_{1}(S)=S^{1 / 2}$, we have

$$
U_{2}(S)=\operatorname{Max}_{\substack{o \leqslant s_{2} \leqslant S \\ o \leqslant k_{1,2} \leqslant 1}}\left\{s_{2}^{1 / 2}+v\left[p\left(S-s_{2}+k_{1,2}\right)^{1 / 2}+q\left(S-s_{2}-k_{1,2}\right)^{1 / 2}\right]\right\}
$$

We must determine the values of $k_{1,2}$ and $s_{2}$ maximising the expression in braces.

The condition of first order with respect to $s_{2}$ is:

$\frac{\delta\{\cdots\}}{\delta s_{2}}=\frac{1}{2} s_{2}^{-1 / 2}-\frac{1}{2} v\left[\left(S-s_{2}+k_{1,2}\right)^{-1 / 2} \cdot p+\left(S-s_{2}-k_{1,2}\right)^{-1 / 2} \cdot q\right]$

Let it be equal to zero. We have:

$$
\left(S-s_{2}+k_{1,2}\right)^{-1 / 2} \cdot p+\left(S-s_{2}-k_{1,2}\right)^{-1 / 2} \cdot q=\frac{s_{2} 2^{-1 / 2}}{v}
$$


Doing the same with respect to $k_{1,2}$, we have:

$\frac{\delta\{\cdots\}}{\delta k_{1,2}}=\frac{1}{2} v \cdot\left[\left(S-s_{2}+k_{1,2}\right)^{-1 / 2} \cdot p-\left(S-s_{2}-k_{1,2}\right)^{-1 / 2} \cdot q\right]=0$

or

$$
k_{1,2}=\left(S-s_{2}\right) \cdot \frac{p^{2}-q^{2}}{p^{2}+q^{2}}
$$

The relation (I) may be written, because of (2)

$$
2\left(S-s_{2}-k_{1,2}\right)^{-1 / 2} \cdot q=\frac{s_{2}^{-1 / 2}}{v}
$$

Replacing $k_{1,2}$ by the value (3), we have:

$$
s_{2}=\frac{S}{\mathrm{I}+2 v^{2} \cdot\left(p^{2}+q^{2}\right)}
$$

The values of $k_{1,2}$ and $s_{2}$ give $U_{2}(S)$. Indeed, the expression $A h^{2}+2 B h k+C k^{2}$, where

$$
A=\frac{\delta^{2}\{\ldots\}}{\delta s_{2}^{2}} ; B=\frac{\delta^{2}\{\ldots\}}{\delta s_{2} \delta k_{1,2}} ; C=\frac{\delta^{2}\{\ldots\}}{\delta k_{1,2}^{2}}
$$

has compoundroots and $A<0$.

The value of $U_{2}(S)$ is given by

$$
U_{2}(S)=S^{1 / 2} \cdot\left[\mathrm{I}+2 v^{2}\left(p^{2}+q^{2}\right)\right]^{1 / 2}
$$

The condition $0 \leqslant s_{2} \leqslant S$ is always verified by (4).

The condition $0 \leqslant k_{1,2} \leqslant \mathrm{I}$ is, because (3) and (4)

$$
0 \leqslant \frac{2 S v^{2}\left(p^{2}-q^{2}\right)}{\left[\mathrm{I}+2 v^{2}\left(p^{2}+q^{2}\right)\right]} \leqslant \mathrm{I}
$$

The first inequality is always verified $(p>q)$.

The second inequality is

$$
\begin{gathered}
S \leqslant \frac{I+2 v^{2}\left(p^{2}+q^{2}\right)}{2 v^{2}\left(p^{2}-q^{2}\right)} \\
U_{3}(S)=\operatorname{Max}_{\substack{o \leqslant s_{3} \leqslant S \\
o \leqslant k_{1,3} \leqslant 1}}\left\{s_{3}^{1 / 2}+v\left[p U_{2}\left(S-s_{3}+k_{1,3}\right)+q U_{2}\left(S-s_{3}-k_{1,3}\right)\right]\right\}
\end{gathered}
$$


As $U_{2}(S)=S^{1 / 2} \cdot\left[I+2 v^{2}\left(p^{2}+q^{2}\right)\right]^{1 / 2}$, we have

$$
\begin{aligned}
& U_{3}(S)=\operatorname{Max}\left\{s^{1 / 2}+v\left\lceil p\left(S-s_{3}+k_{1,3}\right)^{1 / 2}+q\left(S-s_{3}-k_{1,3}\right)^{1 / 2}\right\rfloor \cdot\right.
\end{aligned}
$$

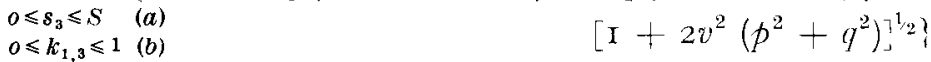

Repeating the operations for $U_{3}(S)$, we have

$$
\begin{aligned}
k_{1,3} & =\left(S-s_{3}\right) \cdot \frac{p^{2}-q^{2}}{p^{2}+q^{2}} \\
s_{3} & =\frac{S}{\mathrm{I}+2 v^{2}\left(p^{2}+q^{2}\right)} \overline{+\left\lceil 2 v^{2}\left(p^{2}+q^{2}\right)\right]^{2}} \\
U_{3}(S) & =S^{1 / 2}\left\{\mathrm{I}+2 v^{2}\left(p^{2}+q^{2}\right)+\left[2 v^{2}\left(p^{2}+q^{2}\right)\right]^{2}\right\}^{\prime 2}
\end{aligned}
$$

The condition $(a) 0 \leqslant s_{3} \leqslant S$ is always verified.

The condition $(b)$ is now:

$$
S \leqslant \frac{I+\left[2 v^{2}+\left(2 v^{2}\right)^{2} \cdot\left(p^{2}+q^{2}\right)\right] \cdot\left(p^{2}+q^{2}\right)}{\left[2 v^{2}+\left(2 v^{2}\right)^{2} \cdot\left(p^{2}+q^{2}\right)\right] \cdot\left(p^{2}-q^{2}\right)} \delta \leqslant
$$

Since we have used the formula

$$
U_{2}\left(S-s_{3}+k_{1,3}\right)=\left(S-s_{3}+k_{1,3}\right)^{1 / 2} \cdot\left[\mathrm{I}+2 v^{2}\left(p^{2}+q^{2}\right)\right]^{1 / 2}
$$

we must consider yet another condition

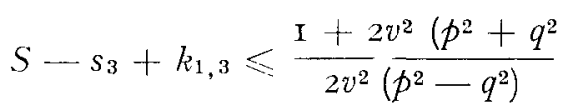

or

$$
\begin{gathered}
S \leqslant(\mathrm{I}) \times \frac{\mathrm{I}+2 v^{2}\left(p^{2}+q^{2}\right)}{2 p^{2} \cdot 2 v^{2}} \delta \leqslant \\
U_{N}(S)=S^{1 / 2}\left\{\mathrm{I}+2 v^{2}\left(p^{2}+q^{2}\right)+\left[2 v^{2}\left(p^{2}+q^{2}\right)\right]^{2}+\ldots+\right. \\
\left.-\left[2 v^{2}\left(p^{2}+q^{2}\right)\right]^{N-1}\right\}^{1 / 2} \\
k_{1, N}=\left(S-s_{N}\right) \cdot \frac{p^{2}-q^{2}}{p^{2}+q^{2}} \\
S \\
s_{N}=\frac{S}{\mathrm{I}+2 v^{2}\left(p^{2}+q^{2}\right)+\left[2 v^{2}\left(p^{2}+q^{2}\right)\right]^{2}+\ldots+\left[2 v^{2}\left(p^{2}+q^{2}\right)\right]^{N}-}
\end{gathered}
$$


We have $N$ - I conditions concerning $S$ :

$$
\begin{aligned}
& S \leqslant \frac{\mathrm{I}+\left[2 v^{2}+\left(2 v^{2}\right)^{2} \cdot\left(p^{2}+q^{2}\right)+\ldots+\left(2 v^{2}\right)^{N-1} \cdot\left(p^{2}+q^{2}\right)^{N-2}\right] \cdot\left(p^{2}+q^{2}\right)}{\left[2 v^{2}+\left(2 v^{2}\right)^{2} \cdot\left(p^{2}+q^{2}\right)+\ldots+\left(2 v^{2}\right)^{N-1} \cdot\left(p^{2}+q^{2 N-2]} \cdot\left(p^{2}-q^{2}\right)\right.\right.} \\
& \delta \leqslant \quad(\mathrm{I}) \\
& \quad \quad S \leqslant(\mathrm{I}) \cdot \frac{\mathrm{I}}{\left(2 p^{2}\right) \cdot\left(2 v^{2}\right)} \cdot \frac{\left(2 v^{2}\right)^{N-1} \cdot\left(p^{2}+q^{2}\right)^{N-1}-\mathrm{I}}{\left(2 v^{2}\right)^{N-1} \cdot\left(p^{2}+q^{2}\right)^{N-2}-\mathrm{I}} \delta \leqslant(2) \\
& \quad S \leqslant(\mathrm{I}) \cdot \frac{\mathrm{I}}{\left(2 p^{2}\right)^{N-2} \cdot\left(2 v^{2}\right)^{N-2}} \cdot \frac{\left(2 v^{2}\right)^{N-1} \cdot\left(p^{2}+q^{2}\right)^{N} 1-\mathrm{I}}{2 v^{2} \cdot\left(p^{2}+q^{2}\right)-\mathrm{I}} \delta \leqslant(N-\mathrm{I})
\end{aligned}
$$

To consider an infinite horizon, let us take $N$ infinite.

We have

$$
s_{\infty}=\lim _{N \rightarrow \infty} s_{N}=\frac{S \cdot\left[2 v^{2}\left(p^{2}+q^{2}\right)-\mathrm{I}\right]}{\lim _{N \rightarrow \infty}\left[2 v^{2}\left(p^{2}+q^{2}\right)\right]^{N}-\mathrm{I}}
$$

The value of $s_{\infty}$ depends on $\lim _{N \rightarrow \infty}\left[2 v^{2}\left(p^{2}+q^{2}\right)\right]^{N}$

We have:

a)

$$
2 v^{2}\left(p^{2}+q^{2}\right)<\mathrm{I}
$$

$$
12<p<(u / 2) \quad S \leqslant \frac{\mathrm{I}}{2 v^{2}\left(p^{2}-q^{2}\right)}
$$$$
s_{\infty}=S\left[\mathbf{I}-2 v^{2}\left(p^{2}+q^{2}\right)\right] ; k_{1, \infty}=2 S v^{2}\left(p^{2}-q^{2}\right) ; U_{\infty}(s)=S^{1 / 2} .
$$

$$
\frac{\mathrm{I}}{\left[\mathrm{I}-2 v^{2}\left(p^{2}+q^{2}\right)\right]^{1 / 2}}
$$

$$
(u / 2)<p<\frac{v+\left(\mathrm{I}-v^{2}\right)^{1 / 2}}{2 v}-S=0 \quad s_{\infty}=k_{1, \infty}=U_{\infty}(S)=0
$$

b)

$$
\begin{gathered}
2 v^{2}\left(p^{2}+q^{2}\right) \geqslant \mathrm{I} \text { or } p \geqslant \frac{v+\left(\mathrm{I}-v^{2}\right)^{1 / 2}}{2 v} \\
S=0 \quad s_{\infty}=k_{1, \infty}=U_{\infty}(S)=0
\end{gathered}
$$

$s_{\infty}=k_{1, \infty}=U_{\infty}(S)=0$ means the whole portfolio must be reinsured; there are no dividends and the dividends' utility is zero. 


\section{Remark}

If the conditions concerning $S$ are not verified, we must take values of $k_{1}$ other than those giving $U(S)$.

For example, if $N=2$ and if $S>\frac{\mathrm{I}+2 v^{2}\left(p^{2}+q^{2}\right)}{2 v^{2}\left(p^{2}-q^{2}\right)}$, the calculated value of $k_{1,2}$ would be bigger than $\mathrm{I}$.

In this case, we may take the value $k_{1,2}$ of the reinsurance treaty and determine the value of $s_{2}$ giving the dividends' average utility.

It will now be of prime interest:

to determine the appropriate utility functions,

to suppress some hypotheses,

to consider more variables in order to obtain better fitted models

\section{RLFERENCES}

[1] Bellman R (1961). "Adaptive Control Processes. A guvded tour". Princeton University Press, Princeton, N. J.

[2] BoRch K H (196I). "The utility concept applied to the theory of insurance" Astin Bull. I. 245-255

L3] Borch K H (1964a) "Payment of duvdend by insurance companes" Trans XVII Intern Cong Actu London, 3, 527-540.

[4] BоRсH K H (1964b). "The optrmal management polvcy of an insurance company". Proc Casualty. Actu. Soc., 5I, I82-197.

[5] BORCH K H (1968) "The Economics of Uncertanty". Princeton Studies in Mathematical Economics nr 2 Princeton Uंnıversity Press. 227p.

[6] Borch K. H (I972). "Risk management and Company objectrves". Trans. XIX Intern Cong Actu. Oslo, 4, 6I3-6I9

[7] Hakansson Nils. H. (I966). "Optimal investment and consumption strategies for a class of utılity functions". PH. D. Dissertation, Unıversity of Californıa Worhing paper nr IoI Western Management Science Institute, University of California

'8] Seal H I. (I969) "Stochastic Theory of a Risk Busıness". Yale UniversityWiley; XIII-2 Iop.

9] WOLFF K H (1966) "Collective theory of rnsk and utilnty functions". Istin Bull IV 6 -IO 